\title{
La mirada de los jóvenes sobre el castigo penal en la Provincia de Buenos Aires, Argentina (2015)
}

\author{
Mariana Cecilia Fernández, Ph.D. \\ Profesora Universidad Nacional de la Matanza, \\ Argentina*
}

mcf.mariana@gmail.com

\section{Resumen (descriptivo)}

El objetivo de este trabajo es dar cuenta de los discursos de jóvenes bajo medidas alternativas a la privación de libertad sobre el castigo en el encierro y el castigo en libertad. El análisis tiene lugar a través de un estudio de caso radicado en un Centro de Referencia de la Provincia de Buenos Aires en 2015. Para ello, se emplea una metodología cualitativa que se vale de técnicas de entrevista en profundidad y se analizan los discursos desde una perspectiva cultural de la cuestión criminal. Algunos resultados del estudio nos permiten afirmar que los jóvenes perciben a las medidas alternativas como un castigo preferible a la privación de libertad no solo por su ineficacia resocializadora sino por los efectos altamente estigmatizantes que supone el encierro penal.

\section{Palabras clave}

Juventud, castigo, discurso, medidas alternativas a la privación de libertad.

\section{Thesauro}

Tesauro de Ciencias Sociales de la Unesco.
Para citar este artículo

Fernández, M. C. (2019). La mirada de los jóvenes sobre el castigo penal en la Provincia de Buenos Aires (2015). Revista Latinoamericana de Ciencias Sociales, Niñez y Juventud, 17(2), 1-30. doi:

10.11600/1692715x.17215

Historial

Recibido: 26.09.2018

Aceptado: 14.01.2019

Publicado: 26.04.2019

Información artículo

Este artículo se basa en la investigación realizada por la autora con la financiación del Consejo Nacional de Investigaciones Científicas y Técnicas (Conicet, Expediente $\mathrm{N}^{\circ}$ 006492/12). La investigación se inició el 1 de marzo de 2014 y culminó el 12 de diciembre de 2016. Área: Ciencias Sociales. Subárea: sociología. 


\section{What young people think about criminal punishment in Buenos Aires, Argentina}

$$
\text { (20I5) }
$$

\section{Abstract (descriptive)}

The objective of this study is to account for the discourses of youth in juvenile detention centers about punishment in jail and punishment when they are free. The analysis is produced through a case study from a Referral Centre located in Buenos Aires province in 2015. The authors use a qualitative methodological approach that involves in-depth semi-structured interviews and discourses are analyzed based on seeing criminality through a cultural perspective. The results of the study allow us to affirm that young people perceive alternative measures as a preferable punishment to being confined in a juvenile detention centre, not just because it is inefficient in achieving its goal of re-socialization, but also because of the high level of stigmatization associated with criminal imprisonment.

\section{Keywords}

Youth, punishment, discourse, non-custodial sanctions.

\section{O olhar dos jovens sobre a punição penal na Província de Buenos Aires, Argentina (2OI5)}

Resumo (descritivo)

O objetivo deste trabalho é dar conta dos discursos de jovens, sob medidas alternativas à privação da liberdade sobre punição no confinamento e punição em liberdade. A análise se dá por meio de um estudo de caso baseado em um Centro de Referência da Província de Buenos Aires em 2015. Para isso, utiliza-se uma metodologia qualitativa que utiliza técnicas de entrevista em profundidade e os discursos são analisados a partir de uma perspectiva cultural da questão penal. Alguns resultados do estudo nos permitem afirmar que os jovens percebem medidas alternativas como uma punição preferível à privação de liberdade não apenas por causa de sua ineficácia na ressocialização, mas também por causa dos efeitos altamente estigmatizantes da prisão criminal.

\section{Palavras-chave}

Juventude, punição, discurso, medidas alternativas à privação de liberdade.

\section{Información autora}

[*] Doctora en Ciencias Sociales y Licenciada en Ciencias de la Comunicación (Facultad de Ciencias SocialesUniversidad de Buenos Aires). Becaria posdoctoral del Conicet y del Instituto de Investigaciones Gino Germani. Profesora de la Universidad Nacional de la Matanza, Argentina. Orcid: 0000-0003-3905-9432. Índice H5: 6. Correo electrónico: mcf.mariana@gmail.com. 


\section{Introducción}

«Para mí el castigo está para que la gente aprenda a no tocar las cosas que no son suyas, a hacer buena letra, a respetar. Pero el encierro es lo peor». Contundente, el testimonio de un joven bajo una medida alternativa a la privación de libertad sugiere algunas de las finalidades del castigo penal: resguardo de la propiedad privada, respeto a los valores morales sobre los que esta última se erige, exclusión de la amenaza que supondría dejar impune un acto socialmente reprobable. Como diría Durkheim (2004), la función de la pena es educar al conjunto de la población en el respeto a la norma a través del temor al castigo, el cual recuerda las prohibiciones transgredidas y concientiza respecto de las implicancias de violarlas. La expulsión simbólica del criminal detiene el curso de los afectos que podrían llegar a atentar contra las formas existentes de solidaridad, reafirma la inviolabilidad de la regla transgredida y certifica las formas de sentir y de pensar que comparten los miembros de una sociedad.

Lo hace mediante la aplicación de dolor (Cesaroni, 2010), en ocasiones en espacios segregados de la sociedad que impiden la reinserción social (Baratta, 1990; Bergalli, 2003; Pavarini, 2006; O’ Malley, 2006).

Ahora bien, ¿qué sucede en el contexto de la ejecución de medidas alternativas a la privación de libertad?, ¿cómo conciben las acciones institucionales y comunitarias pertinentes en el marco de su implementación los propios jóvenes intervenidos?, ¿qué diferencias vislumbran entre los diferentes tipos de intervención?, ¿las piensan en términos sancionatorios?, ¿qué sentidos adopta el significante de castigo en los discursos juveniles?, ¿se trata de un castigo de tipo penal orientado a excluir al sujeto transgresor?, ¿o de un castigo moral tendiente a reintegrarlo a la comunidad? Estos son los interrogantes principales que guiaron la investigación. ${ }^{1}$

\footnotetext{
${ }^{1}$ Investigación que forma parte de una tesis doctoral sobre la construcción social de la categoría socio-jurídica de responsabilidad penal juvenil producida entre los discursos institucionales, los discursos comunitarios y los discursos juveniles en el marco de la implementación de medidas alternativas a la privación de libertad.
} 
Si bien el tema del castigo penal juvenil ha sido extensamente trabajado por investigaciones centradas en los discursos y prácticas de los agentes institucionales que implementan estrategias de control o «resocialización» sobre los jóvenes (Guemureman, 2008; López, 2012; Lucesole, 2012; Nicoletti, 2014; Oyhandy-Cioffy, 2004; Uriarte, 2013), son pocos los trabajos que relevan la opinión de los propios jóvenes intervenidos (Cesaroni, 2010; Corbalán \& Rodríguez-Alzueta, 2016; Kessler, 2004; Medan, 2012; Tonkonoff, 2007a, 2007b.;) y muchos menos los que lo hacen en el contexto de la implementación de medidas en libertad (Tenembaum, 2015). En tal sentido, este artículo se propone aportar a ese campo emergente de estudios a partir de un estudio de caso en la Provincia de Buenos Aires. Utilizando como marco teórico una aproximación cultural de la cuestión criminal (Tonkonoff, 2012), buscamos analizar el carácter de las medidas alternativas al encierro desde la perspectiva de sus destinatarios.

Esta cuestión nos permitirá elaborar un conjunto de consideraciones específicas sobre los procesos de transformación o aggiornamento de la cultura de la penalidad juvenil subyacente al nuevo paradigma de la responsabilidad inaugurado a partir de la sanción de las leyes de Promoción y Protección Integral de los Derechos del Niño (№ 13 298)2 (Congreso de la Nación Argentina, 2019) y su accesoria, la ley № 13634 (Congreso de la Nación Argentina, 2019), que crea en la Provincia de Buenos Aires el Fuero de Responsabilidad Penal Juvenil y el Fuero de la Familia. Los cambios normativos son importantes porque transforman, legalmente, la concepción del joven como sujeto «menor», herencia del modelo de Patronato que privaba a los/as jóvenes transgresores de su condición de sujetos de derechos (Andrés-Candelas, 2016), desde las primeras décadas del siglo XX en Argentina. Sin embargo, como sostienen Valdenegro y Calderón-Flández (2016) respecto de los discursos de interventores sociales que operan en el marco de programas de libertad asistida en Chile, en la construcción social de las infancias perduran «polaridades en tensión»: aquellas que, por un lado, configuran la identidad de los/as jóvenes como sujetos «permeables versus duros» y sujetos «autoactualizables versus carenciados», dando lugar a tensiones también en las propias prácticas interventivas, en las que muchas veces los interventores naturalizan la concepción del sujeto intervenido desde lo programático.

Lo hacen en un contexto local, regional y mundial signado por la demanda ciudadana de inseguridad atribuida al joven pobre (Guemureman, 2008). Demandas que promu2 La Ley de Promoción y Protección Integral de los Derechos del Niño, sancionada el 12/12/2006, deroga la No
10067 que reproducía la denominada Ley de Patronato ( $\mathrm{N}^{\mathrm{o}} 10$ 903) vigente desde 1919 en el país. 
even la privación de la libertad de jóvenes infractores a fin de calmar las ansiedades de la ciudadanía pero que no contribuyen a solucionar el problema de la inseguridad pública ni a suscitar la tolerancia a la transgresión en la convivencia ciudadana (GionzálezLaurino, 2015). El incremento de la sensibilidad social sobre el crimen producido por jóvenes genera reacciones en la opinión pública orientadas al endurecimiento de las penas, la baja en la edad de punibilidad y otras medidas punitivas (Komatsu \& Bazon, 2015).

Los cambios normativos son importantes, además, porque introducen desde 2008 en la Provincia de Buenos Aires la aplicación de medidas alternativas a la privación de libertad, cuyo fin principal es evitar que los jóvenes infractores de la ley sean encerrados en instituciones que los separen de sus familias y del resto de la sociedad. Instituciones cuyo tránsito afecta a quienes las recorren mediante la generación de marcas estigmatizantes (Anitua, 2014; Goffman, 2010; Rodríguez-Alzueta, 2014).

Los efectos criminógenos generados por la privación de libertad son contemplados por una política pública «alternativa», orientada por la finalidad de «responsabilizar»a los jóvenes e incluso a sus familias, hacia quienes se promueve la corresponsabilidad. ${ }^{3}$ Siguiendo a Ávila-Navarrete (2017), las familias deben hacerse presentes activa y responsablemente durante los procesos de intervención penal juvenil fomentando la creación de escenarios de afecto, colaboración, conocimiento y conductas socialmente proactivas. Así, la cuestión de la infracción penal juvenil abre múltiples discusiones atenientes a distintas dimensiones de la vida de los/as jóvenes tales como las condiciones sociales, familiares y el uso de drogas (Jiménez, Meireles-Andrade, \& Guimarães Batistella Bianchini, 2016).

Ello sucede en el marco de la ampliación de las redes del control que supone el modelo de justicia intervencionista bajo el cual surgen estas medidas (López et al., 2009). Medidas cuyo tránsito, el joven debe atravesar obligatoriamente a fin de evitar la privación de la libertad y cuyo carácter puede ser reintegrativo (Braitwaite, 2011) o penal (Tonkonoff, 2012) de acuerdo al modo en que tenga lugar la intervención. Desde una

3 El fin de las medidas alternativas es «fomentar el sentido de responsabilidad del niño y orientarlo en un proyecto de vida digno, con acciones educativas que se complementarán con la intervención de la familia, la comunidad y el Municipio respectivo, con el apoyo de los especialistas que el Juez determine». Tales acciones se deben realizar a partir de la ejecución de convenios entre la autoridad de aplicación provincial, los Municipios e instituciones de la comunidad (Ley 13 634/ art. 69) (Congreso de la Nación Argentina, 2019). 
perspectiva cultural de la cuestión criminal ${ }^{4}$, partimos del supuesto según el cual una estrategia de intervención es penal cuando se dirige al joven a través de discursos que persiguen, pasional y colectivamente, la expulsión simbólica del joven como criminal, en forma institucionalizada o no (Tonkonoff, 2012); a diferencia de cuando se promueven procesos de confrontación reintegrativa (Braitwaite, 2011) mediante los cuales se transmite la deshonra que conlleva la transgresión sobre la base de un trato afectuoso y respetuoso del sujeto intervenido que puede incentivarlo a desistir del delito en el marco de una política de restitución de derechos.

Ahora bien: ¿es la accesibilidad a derechos equitativa para todos los jóvenes por igual en la Argentina contemporánea?, ¿se distribuyen los derechos de igual forma a lo ancho y lo alto de la pirámide social? En relación al último interrogante, González-Laurino (2015) afirma que los jóvenes sobre los que se interviene en el marco de la implementación de medidas alternativas a la privación de libertad son aquellos que se corresponden con el estereotipo criminal (varón, pobre, morocho, de bajo nivel educativo, que comete delitos predominantemente contra la propiedad). Ello, sumado a que en razón del tipo de delito y de que por lo general es la primera vez que son atrapados por el sistema penal permite derivar que dichos jóvenes no hubiesen requerido intervención bajo la vigencia de los ex juzgados de menores.

Una intervención que, sostiene Beloff (2002), puede impactar positivamente en el joven en tanto valor adicional pero no porque sea el principio en que se funda. En sus propios términos:

Es de suma importancia reconocer que estos sistemas se encuentran dentro del orden de ideas en el que opera el sistema penal; de otro modo se lo descontextualizaría como se hacía en el modelo tutelar en el que el fundamento de toda intervención era "proteger» al menor. Muchos integrantes de la nueva justicia juvenil no enmarcan su práctica en esta lógica y, en muchos casos, interpretan su función como dirigida a ayudar a los adolescentes con derechos amenazados o violados, bajo la excusa de que el sistema de protección no da respuestas adecuadas (Beloff, 2002, p. 120).

\footnotetext{
4 Esta aproximación tiene su punto de partida en Durkheim (1982) y Tarde (1952), se nutre de elementos del psicoanálisis tanto freudiano como lacaniano y de las teorías posestructuralistas del discurso y la semiosis social. Para una articulación de estas tradiciones en el ámbito de la cuestión criminal nos basamos en Tonkonoff (2012).
} 
$\mathrm{Al}$ respecto, advierte Uriarte (2013), la exigua orientación al reproche penal que suele predominar en la implementación de la Justicia Penal Juvenil se vincula con una perspectiva aproblemática sobre la selectividad del sistema penal y judicial hacia su clientela principal: el joven pobre. De aquí la pregunta por el modo en que un sistema procesal ideado como de mínima intervención punitiva puede acabar por extender y formalizar el alcance de las redes de coacción punitiva sobre jóvenes pertenecientes a los sectores populares (Axat \& Rodríguez-Alzueta, 2014). Al respecto, Daroqui señala que el peligro que corren las políticas públicas que apuntan a la integración de los jóvenes en un marco de exclusión generalizada es el de ampliar las redes de control alli «donde no se les da nada de lo que les falta: ni trabajo, ni educación ni salud, donde llega al delito como una forma más de esa exclusión» (1995, p. 74). Se trata de lo que Tenembaum (2016) denomina «refuncionalismo», cuando señala la búsqueda de la reinserción social de los jóvenes sin modificar las condiciones mediatas de la infracción.

La implementación de medidas alternativas a la privación de libertad se da en Argentina en un escenario donde priman la escasez de recursos, las pugnas políticas y la desarticulación de los actores (Lucesole, 2012). En este marco, sostiene López et al. (2009) se detecta una gran indeterminación entre el ámbito penal y el asistencial, que no termina de desterrar la perspectiva tutelar vinculada a la díada «represión-compasión», que busca superar el modelo de derechos implantado con la Convención de los Derechos del Niño. Ello, sumado a la convivencia paradójica del Régimen Penal de la Minoridad, a escala nacional, y la Ley de Responsabilidad Penal Juvenil (n.. 13 634), en la Provincia de Buenos Aires, da lugar a una utilización legal vacilante, en un sentido tutelar o de restitución de derechos (Nicoletti, 2014, p. 76).

\section{Método}

Para llevar a cabo los objetivos de la investigación se utilizó un enfoque metodológico cualitativo, el cual se valió de técnicas de entrevista semi-estructurada en profundidad a jóvenes de 16 y 17 años que acudían a un Centro de Referencia de la Provincia de Buenos Aires.5 El Centro de Referencia se encuentra ubicado en un lugar neurálgico de uno de los partidos de zona oeste más importantes del Gran Buenos Aires, a pocas cuadras de la estación de tren y rodeado de negocios, organismos públicos, bancos y bares.

5 La duración de la medida puede variar de 6 meses a 2 años, de acuerdo a lo que disponga el juez. 
Visto desde afuera, no parece un dispositivo ambulatorio penal. De hecho, ningún cartel lo indica. Solo puede percibirse un indicio de que funciona un «centro de día» en el marco de un colorido mural emplazado en uno de los laterales de la esquina donde se sitúa. Ex delegación de minoridad, abre a las 8 de la mañana y alrededor de las cuatro de la tarde, en general, ya no queda personal. Se atiende a 118 jóvenes comprometidos penalmente en la consumación de delitos leves (cuya pena es menor a dos años de prisión) y no tienen antecedentes penales previos, debido a lo cual el juez les otorga una medida alternativa a la privación de la libertad 6 ; un 5.3 por ciento del total de jóvenes bajo ese régimen de responsabilidad que llega en 2015 a una cantidad de 2200 jóvenes a nivel provincial, de acuerdo a datos de la Secretaría de Niñez y Adolescencia ${ }^{7}$.

Desde una perspectiva legal, los jóvenes enviados al Centro de Referencia pueden hallarse bajo una medida cautelar o sancionatoria alternativa a la privación de la libertad. Son medidas cautelares aquellas supeditadas a una investigación penal preparatoria (IPP) durante la primera parte del proceso y medidas sancionatorias, aquellas que se imponen al finalizar el transcurso de la medida cautelar con la elevación de la causa a juicio. Si el joven no efectúa las condiciones impuestas por el juez, al cumplir la mayoría de edad su causa es elevada al Fuero de Responsabilidad Penal Juvenil, que es donde se

\footnotetext{
${ }^{6}$ Los jóvenes de 16 y 17 años solo pueden ser penados con pena de privación de la libertad mayor a dos años, por delitos tales como el homicidio, robo con armas o venta de estupefacientes.

7 Según esta última fuente, los jóvenes alojados en centros cerrados, es decir, privados de libertad, alcanzan una cifra mucho menor, de 480 casos en su totalidad, y los sujetos a medidas abiertas o de semilibertad (esto es, alojados en Centro de Recepción o Centros de Contención) alcanzan solo a 110 casos. De modo que, si esto es así, y en toda la provincia de Buenos Aires hay 2790 jóvenes cumpliendo medidas de responsabilidad penal (ya sean privativas, restrictivas o alternativas a la privación de la libertad), aquellos que asisten a Centros de Referencia representan un $78.85 \%$ del total. Para mayor información, véase el sitio web de la Secretaría de Niñez y Adolescencia de la Provincia de Buenos Aires: www.snya.gba.gov.ar
} 
termina de definir su situación legal. Este procedimiento sucede tanto para la imposición de medidas que suponen encierro como para las alternativas. ${ }^{8}$

Nos propusimos realizar un estudio de caso en dicha institución debido a la utilidad de la estrategia para examinar un fenómeno de carácter general que es posible comprender mediante la indagación de los discursos de los/as actores sociales que lo constituyen y, por tanto, lo producen y transforman. Los entrevistados/as fueron once: Agustín, Franco, Cristian, Iván, Lucas, Martín, Mauro, Lucía, Leonel, Brian y Pablo, de los cuales dos estuvieron acompañados/as por su madre durante el transcurso de la charla y uno, por un amigo. Sus verdaderos nombres fueron cambiados para resguardar su identidad pues aunque en rigor de verdad no se lo preguntamos, la mayoría lo mencionó por motivación propia en algún momento.

El trabajo de campo se desarrolló entre marzo y agosto de 2015 en un bar ubicado enfrente de la institución y se dividió en dos momentos. En el primero de ellos, de carácter exploratorio, nos dirigimos a la puerta del establecimiento y esperamos que los/as jóvenes salieran de las entrevistas mantenidas con los agentes del centro. Paso seguido, nos presentamos como estudiantes de la universidad que estábamos haciendo una investigación sobre el funcionamiento de los Centros de Referencia para la cual resultaba de suma importancia contar con la opinión de los jóvenes bajo medidas alternativas, la cual era anónima. En esta primera instancia realizamos dos entrevistas en profundidad a partir de una guía de pautas «piloto» que elaboramos a modo de prueba. La guía incluyó

8 De acuerdo a lo estipulado en la Ley 13 634, todo niño punible, imputado de delito en la jurisdicción provincial (art. 32) ingresa al Sistema Penal Juvenil, ya sea detenido por la policía (por flagrancia o investigación sumarial) o denuncia ante la fiscalía. Seguidamente del arresto, se inicia la investigación penal preparatoria (IPP), debiéndose comprobar la edad del detenido y avisar a los adultos responsables del niño la existencia de la investigación y los cargos que se le imputan para que ejerza el derecho de defensa (art. 49). También se le debe avisar de la aprehensión al Agente Fiscal, al Defensor Oficial y al Juez de Garantías, indicando el motivo, el lugar donde se encuentre y el sitio donde será conducido. Si el Agente Fiscal lo pide al Juez de Garantías del joven, se podrá ordenar la detención del niño en el plazo de doce (12) horas desde el momento de la aprehensión (art. 41) en centros especializados (Centros de Recepción o alcaldías) (art. 46). En el plazo de los próximos 5 días se fija una audiencia oral para decidir la procedencia de la prisión preventiva o de una medida ambulatoria, en causas graves y si el Agente Fiscal lo solicita al Juez de Garantías (art. 43). En la audiencia del quinto día, se informa al niño el delito por el cual se lo acusa y, si se llega a un acuerdo entre las partes o el juez no halla mérito para que continúe la detención, puede decretar la libertad del niño procesado (art. 50) y la causa se archiva. De lo contrario, el juez puede imponerle una o varias de las siguientes medidas cautelares: prohibición de salir del país, de la localidad en la cual residiere o del ámbito territorial que el Juez determine; prohibición de asistir a determinadas reuniones, recintos o espectáculos públicos, o de visitar determinados lugares; prohibición de aproximarse al ofendido, a su familia o a otras personas; prohibición de comunicarse con determinadas personas, siempre que no se afecte el derecho de defensa; obligación de concurrir periódicamente al Tribunal o ante la autoridad que el Juez determine; arresto domiciliario; prisión preventiva (art. 42). Las primeras 5 medidas cautelares mencionadas se cumplen en Centros de Referencia o Centros de Contención. 
preguntas abiertas (informativas, temáticas y evaluativas) que permitieron delimitar las dimensiones del problema, probar y ajustar los instrumentos de análisis en esta primera fase exploratoria y comenzar a elaborar la guía de pautas estandarizada. Esto es, una serie de ejes que tratamos bajo diferente orden en la siguiente fase de la investigación, en forma flexible y generalmente sin tener el cuestionario en mano sino las preguntas principales en mente.

Tanto en esta fase, exploratoria, como a lo largo del trabajo de campo, desgrabamos las entrevistas en simultáneo a nuestra presencia en el campo. Dicho procedimiento nos sirvió para reconocer alusiones significativas referidas por los informantes no puntualizadas en profundidad durante las entrevistas y que tuvimos la oportunidad de retomar a posteriori a fin de explorarlas con mayor detalle. El desgrabado del material en paralelo al trabajo de campo nos permitió, también, identificar contradicciones en el discurso de un mismo entrevistado, evaluar las propias limitaciones en el modo de formular las preguntas y escuchar con mayor atención al entrevistado.

En un segundo momento pudimos efectuar once entrevistas de alrededor de una hora de duración, las cuales se desarrollaron con la guía de pautas en mano y el grabador sobre la mesa, herramientas que no impidieron la empatía con los entrevistados. Los casos se seleccionaron intencionalmente ${ }^{9}$ cuando los jóvenes salían del Centro de Referencia mediante el empleo de un criterio de inclusión y exclusión de la muestra de participantes que refirió, en primer lugar, a que los/as jóvenes se encontraran cumpliendo una medida alternativa y, en segundo lugar, que hayan acudido al menos tres veces a las entrevistas con los agentes del equipo del Centro de Referencia, a fin de que pudieran tener una opinión formada respecto del modo en que se implementaban. Si era la primera vez, resultaba difícil indagar sobre las cuestiones que nos interesaban de manera que si bien realizamos las entrevistas, las mantuvimos como exploratorias y de control pero no las contabilizamos en los once casos.

En cuanto al instrumento de recolección de datos, se eligió la técnica de entrevista en profundidad en tanto permite acceder al imaginario de los jóvenes sobre los fenómenos en estudio en su propio lenguaje, a fin de comprender su punto de vista (Vasilachis de Gialdino, 2006). La guía de pautas se dividió en tres bloques: el primero abocado a la caracterización del sujeto intervenido en el cual comenzamos pidiéndoles si se podían presentar de la forma en que quisieran y proseguimos consultándoles el tiempo que

9 El muestreo intencional se caracteriza por la inclusión deliberada de grupos típicos en una muestra representativa en función de los intereses temáticos y conceptuales del estudio (Vasilachis de Gialdino, 2006). 
hacía que acudían al Centro de Referencia, si habían ingresado alguna vez a un centro cerrado y hasta cuándo tenían que cumplir la medida; el segundo, dirigido a la caracterización de la intervención en el cual las preguntas se orientaron a indagar qué tareas les habían encomendado hacer, cuál era su finalidad, cómo era la relación con el personal del equipo técnico, si les parecía importante cumplir con los acuerdos establecidos, cuáles eran sus responsabilidades y sus principales desafíos; y el tercero, sobre la caracterización del castigo. Esta es la principal categoría de indagación a la que se aboca este artículo, la cual dividimos en dos subcategorías: castigo moral y castigo penal. El primero, el castigo moral, lo concebimos como aquel al que refieren los enunciados juveniles cuando dan cuenta de las medidas, alternativas y privativas de libertad, en términos reintegrativos (Braithwaite, 2011). Es decir, describiéndolas como orientadas a la integración del joven en la comunidad. El castigo penal, en cambio, lo entendimos como aquel al que refieren los discursos juveniles para caracterizar las medidas como persiguiendo el fin de apartar apartar del nosotros aquello que designan como alteridad cultural radical. Un otro no integrable, un radicalmente otro, un criminal. Para explorar dichas subcategorías les preguntamos a los jóvenes y las jóvenes qué creían que había que hacer con un joven que cometía un delito, cuál consideraban que era la función del castigo, qué cosas habían cambiado en su vida desde que cumplía con la medida alternativa y las diferencias entre una medida alternativa y una medida privativa de libertad.

Al realizar la entrevista buscamos desarrollar una práctica metódica y reflexiva capaz de impedir tanto el automatismo metodológico como la puesta en acción de una abstracción teórica al realizar las preguntas: «verdaderas hipótesis que se apoyan sobre una representación intuitiva y provisional de la fórmula generadora propia del entrevistado para incitarla a develarse más completamente» (Bourdieu, 1993, p. 8). Ello nos permitió vincularnos empáticamente con la mirada de los jóvenes y las jóvenes y la significación puesta en juego en sus discursos, lo cual determinó el alcance de nuestras preguntas y nos permitió anticipar sus razonamientos que - vale aclarar- no siempre confirmaron nuestras expectativas.

\section{Resultados}

\section{Castigo en el encierro y castigo en libertad}

Como hemos mencionado en la introducción del artículo, desde una concepción durkheimiana el castigo penal cumple la función de certificar el conjunto de valores y 
creencias que identifica a un grupo social en contraposición de aquel que, mediante la transgresión de la ley, los viene a amenazar. ${ }^{10}$ Es por eso que criminalizar y castigar penalmente al transgresor no puede más que reanudar el orden quebrantado, en su dimensión simbólica y social. Y, por el contrario, la no aplicación de castigo penal conlleva a que la disciplina pierda autoridad (Durkheim, 1971). Como es nuestra intensión exhibir, el castigo penal puede ejercerse en espacios cerrados (cárceles, institutos, etcétera) o no (medida no privativa de libertad), y no por ello deja de tener un carácter fundamental en la constitución de los límites simbólicos de la sociedad (Tonkonoff, 2012). Ello no quiere decir que no existan castigos morales sino que, desde este enfoque, ellos no cumplen una función estructurante del entramado social.

Precisamente por la diferencia entre estos dos tipos de castigos nos interesaba indagar a jóvenes bajo medidas alternativas a la privación de libertad. La mayoría de ellos y ellas tiene asignada la realización de tareas comunitarias en simultáneo a la asistencia a un centro de atención terapéutica junto al Centro de Referencia, salvo los/as que poseen hijos de quienes se suele priorizar que busquen o mantengan un trabajo remunerado y asistan al centro. Comenzamos preguntándoles por las acciones institucionales y comunitarias pertinentes de desarrollar hacia un joven que comete un delito y cuál había sido su experiencia personal. Veamos dos testimonios correspondientes a dos entrevistas en cada una de las cuales los/as jóvenes destacaron la conveniencia de las medidas alternativas por sobre el encierro por ser castigos de carácter moral (con una finalidad reintegrativa) y no penal (con una finalidad excluyente):

-Del castigo, ¿qué pensás?, ¿cómo lo ves?, ¿para qué está?

-Para mí el castigo está para que la gente aprenda a no tocar las cosas que no son suyas, a hacer buena letra, a respetar, pero el encierro es lo peor. Te lo digo porque tengo familiares, amigos, el encierro te vuelve más loco. A veces en vez de curarte salís más maldito. Mucho encierro, mucha verdugueada de la policía, no salís curado, salís peor.

- ¿Qué habría que hacer, entonces?

-Mandarlos a un instituto abierto. (Cristian)

- ¿A vos qué te parece que habría que hacer con un joven que comete un delito?

10 En sus propios términos: «la función esencial de la pena no es hacer expiar al culpable su falta mediante el sufrimiento ni intimidar por vía conminatoria a sus posibles imitadores sino reforzar las conciencias en las cuales la violación de la regla ha podido y debido necesariamente perturbar la fe incluso aunque no se dieran cuenta» (Durkheim, 1971, p. 184). 
-Que lo encierren en un colegio o en una granja abierta que pueda entrar y salir. O le conseguiría un trabajo o le haría hacer talleres de mecánica.

_ ¿Qué lo encierren o que pueda entrar y salir?

-Yo la solución no creo que sea el encierro porque te llena de dolor, te da mucha soledad, todo lo que le pasa a la familia le pasa a ellos peor porque no pueden hacer nada y eso duele. Vos querés ver a tu familia bien, comerte un buen asado, también eso te lleva a robar. Todo se soluciona con un buen trabajo. (Franco)

Emerge en los discursos juveniles la idea según la cual el castigo se ejerce en defensa de aquellos que poseen bienes, trabajo y pueden «comerse un buen asado» por sobre los que no lo hacen o pueden hacerlo y salen a robar debido a que no «respetan» ese orden de cosas. Si bien se acepta que sea el resguardo de la propiedad privada el valor principal que la ley exige «respetar», no se considera que el castigo adecuado por la consumación de tal delito sea la privación de libertad. Lo que habría que hacer con un joven que comete un delito contra la propiedad sería todo lo contrario al encierro penal: conseguirle trabajo, ofrecerle talleres de oficio, educarlo, mandarlo a un instituto abierto. Ya sea por la propia experiencia de los/as jóvenes o la de conocidos/as que han vivido el encierro penal, no aparece en los discursos la creencia en la denominada resocialización en instituciones cerradas: el aislamiento individual del joven en un espacio alejado de su familia y de los ámbitos de esparcimiento propios de la juventud generaría efectos anímicos (dolor) y psíquicos (locura) imborrables y contraproducentes a la función moralmente aleccionadora del castigo («salís más maldito»).

Así las cosas, la privación de libertad no serviría para «curar», afirman los discursos juveniles, pero sí para producir dolor no solo en el joven reclutado sino también en su familia. Aunque la esencia de la pena no es el sufrimiento, la represión del acto transgresor que la condena genera a través del cumplimiento de ritos negativos, hace sufrir inevitablemente a quien la recibe (Durkheim, 1971, p. 181). Veamos dos enunciados de jóvenes que estuvieron recluidos en relación a los efectos perjudiciales que genera el encierro:

-Yo creo que a los chicos no hay que encerrarlos.

- ¿Por qué?

-Porque no están preparados para la soledad que te espera ahí. Me parece muy injusto, no sirve, salís peor de ahí. Yo hoy por hoy lo único que quiero es que me saquen el arresto y que me dejan caminar tranquilo. Pero bueno, te acostumbras, te vas adaptando. (Pablo) 
-El encierro no ayuda para nada. Un pibe de 17 no está preparado, como tenía yo cuando me mandaron a la alcaldía X, donde había mayores y menores mezclados.

- ¿Era un instituto?

-No sé, era algo feo, como una cárcel. Los pibes que estaban ahí me decían que yo era muy chico para estar ahí. Se peleaban con los maestros, discutían de por qué me habían llevado ahí si yo no tenía la mayoría de edad y ellos decían que yo tenía 18 pero a mí me faltaba para cumplirlos.

- ¿Cómo era ahí adentro?

-Te la tenés que bancar. Tenés que pelear por tu comida, por tu cama, por todo, no podés estar tranquilo nunca. (Brian)

La lógica que guía los discursos enfatiza una cierta falta de proporción entre el merecimiento «justo» de castigo y lo que ocurriría al interior de las instituciones que se encargan de aplicarlo. Una lógica «clásica»11, podríamos decir con Pavarini (2006), sobre la base de la cual se entiende que para «retribuir» el daño causado a la sociedad, el transgresor debe recibir una dosis de sufrimiento proporcional al mismo. Esta equivalencia retributiva entre el castigo y la ofensa, indica el razonamiento de los discursos, no solo no existe, sino que además no puede darse en un dispositivo de encierro. Allí donde los jóvenes tendrían que «pelear por su cama», por la comida, se la tienen «que bancar»y «no están tranquilos nunca». Como sostiene Cesaroni (2009), la aplicación de dolor como método de disciplinamiento proscribe las actitudes solidarias entre los reclusos.

Los institutos «no ayudan», «no sirven para curarte» (fragmento, este último, del discurso médico o positivista en el que el crimen constituye una patología) sino que más bien conllevarían a una acumulación de resentimiento tal que impide la reinserción. «Era algo feo», «está mal», «salís peor», «te vuelve más loco», se argumenta aludiendo al dolor, la soledad y el hecho de no estar preparados los jóvenes para pelear permanentemente por la supervivencia. De aquí que se conciba que los dispositivos de privación de libertad no sirven para educar en la obediencia legal a quienes han actuado por fuera de ella. La entidad del daño ocasionado por jóvenes que atentaron contra la propiedad no aparece en los discursos juveniles como proporcional a la pena privativa de libertad pues el sufrimiento del joven sería excesivo y contraproducente a la reinserción:

${ }^{11}$ Nos referimos a la escuela de derecho clásica, fundada por Jeremy Bentham en Inglaterra y, en Italia, por Césare Beccaria, que da origen a la racionalidad penal moderna. 
-El encierro es feo.

- ¿Por qué?

-Y, porque estás ahí privado de la libertad, estas ahí pensando «la concha de la lora que pum que pam». Te digo porque yo cuando estaba detenido, estaba pensando «la puta madre, qué bajón este gil que me mandó en cana, mirá vos, tengo una rebronca, ahora cuando salga lo voy a cagar a palos». Cada hora que pasaba, más bronca me daba y si vos te ponés a pensar, cada uno de los que salen de estar en cana, salen más resentidos. Apenas salen, salen a la esquina y capaz que llegan a matar, todo, porque salen más resentidos. (Agustín)

Podemos vislumbrar aquí que los/as jóvenes no consideran que el encierro permita alejar a los/as detenidos/as de la transgresión debido a que no solo el dolor vivido inhabilitaría retomar la vida a la salida, sino que el estigma que genera la posesión de antecedentes penales los/as dejaría «fuera de juego», para decirlo en términos bourdeanos. Como sostienen Marcuello-Servós y García-Martínez (2011, p. 50), las instituciones de encierro se caracterizan por la aplicación de técnicas de sometimiento, coerción y domesticación de la personalidad del sujeto que tienden a transformar el «yo marginal» en un «yo prisionizado» que limita la posible resocialización. Si bien la mayoría de los/as jóvenes no se hayan comprometidos exclusivamente con el delito antes de entrar a una institución penal, el encierro concluye el proceso de formación de su identidad marcándolos como delincuentes al tiempo que provoca un efecto contrario a la disminución de los delitos (Tonkonoff, 2007b).

En tal sentido, y atendiendo a lo señalado en los discursos en torno a las «complicaciones» del arresto domiciliario, así como también las del encierro en un instituto, nos podemos preguntar: ¿qué diferencias hay entre ambos tipos de castigos? ¿Cómo incide en la subjetividad de los/as jóvenes la privación de la libertad en un centro cerrado a diferencia del arresto domiciliario de acuerdo a los discursos juveniles? Estos son algunos testimonios de jóvenes que registramos durante la entrevista efectuada a cada uno de ellos y ellas:

Yo estuve 7 meses encerrado, tuve arresto, son bastante estrictos. Te mandan un asistente social y un policía todos los días para que corroboren que estás ahí. Solo cuando te dan las transitorias tenés 3 horas para ir y venir de tu casa. Es distinto a un instituto porque tenés tus cosas, te podés bañar tranquilo, no estás con pibes malditos que la bardean todo el día y no lo podés evitar, pero para mí fue duro tanto encierro (Mauro).

Hay algunos que tienen suerte y otros que no. A mí la jueza me dio la oportunidad de no seguir detenido en un instituto donde todos los días eran iguales: horario para todo, los

Rev.latinoam.cienc.soc.niñez juv. .Vol. 17, No. 2, jul.-dic. de 2019

E-IS S : $2026-7976 \cdot$ http://dx.doi.org/10.1160o/1692715x.17215 
maestros vigilándote, los pibes bardeando. Por suerte me dejaron ir, pero estoy preso en mi casa. No son todos los chicos que tienen casos así. A algunos con arresto no los dejan ni salir para ir al colegio, a mí me dejan por suerte, pero es complicado, me tienen que acompañar, no puedo ir solo (Pablo).

En principio, podemos notar la emergencia en los discursos juveniles de la idea según la cual las intervenciones serían «estrictas» $\mathrm{y}$ «duras» en ambos casos: en el del arresto domiciliario el control lo realiza un asistente social y la policía, mientras que en un instituto el control lo ejercen los «maestros». El arresto domiciliario es concebido como una «oportunidad» porque permite cumplir la sanción junto a la familia, conservar los propios bienes y no sufrir el desapego. Considerando que, de acuerdo a los discursos juveniles, en los casos de arresto domiciliario «tenés tus cosas, te podés bañar tranquilo, no estás con pibes malditos que bardean todo el día y no lo podés evitar», a diferencia de lo que ocurriría en el encierro en una institución del Estado, podemos pensar que el arresto domiciliario supone un castigo que despierta afectos y sensibilidades de menor concentración de violencia que el encierro en una institución estatal. Lo entendemos, entonces, como un castigo moral en el sentido de que busca la reintegración del joven a la comunidad y no su aislamiento y apartamiento social. En los espacios cerrados los/as jóvenes dicen no poder estar tranquilos, robustecer sus resentimientos, verse exigidos a pelear, dando cuenta del alto grado de punitividad desplegada. Quizás por eso, los/as jóvenes prefieren el arresto domiciliario antes que el encierro en un instituto, el cumplimiento de tareas comunitarias por sobre el arresto domiciliario y, en esta línea, la asistencia al Centro de Referencia por sobre la realización de tareas comunitarias. Cito a continuación los registros de las entrevistas que hicimos a dos jóvenes que se hallaban realizando trabajo comunitario al momento de la investigación:

- Por suerte ahora estoy en el Centro de Referencia porque me mandé una macana y estoy pagando por eso.

- ¿Cómo?

- Haciendo trabajo comunitario.

- ¿Te parece justo?

—Y, no sé, porque a mí se me está haciendo largo, pero tampoco quiero estar encerrado, ahí estás con todos pibes que son resentidos.

- ¿Del arresto domiciliario que pensás? 
-Y no sé, yo prefiero el trabajo comunitario porque aunque te hacen laburar de onda, podés andar por la calle.

- ¿Cómo tendría que ser?

-Tendría que ser todo igual, pero sin las tareas comunitarias, como lo que yo hago con Irma de juntarse a hablar y eso, pero no hacer tareas comunitarias. (Agustín)

- ¿Te mandaron a hacer trabajo comunitario?

$-S_{1}^{\prime}$.

- ¿Te parece justa la medida?

—No, a mí me quieren hacer mulear por nada, limpiar.

-iQuiénes?

-Los de la parroquia, con Irma está todo bien, me ayuda, lo que no me gusta es tener que hacer de mulo. (Leonel)

«Estoy pagando por esto»: la lógica que subyace al enunciado es una lógica retributiva. Los discursos juveniles señalan el pesar con que los jóvenes y las jóvenes viven las tareas comunitarias que habitualmente realizan como medio para conseguir el cierre de la causa y aceptan las premisas del retribucionismo según las cuales todo sujeto culpable de un delito merece ser castigado (Anitua, 2014). Del mismo modo, los discursos juveniles coinciden en señalar la preferencia de los jóvenes por una sanción que consista en conversar con el personal del equipo técnico del Centro de Referencia y que las tareas comunitarias duren menos tiempo o no existan:

A mí me gusta venir acá porque, ¿imagínate si me mandaban a un instituto? Ahí hay que pelar. Además, te hace peor, después de que salís ya no podés entrar a ningún lado por los antecedentes. Mi primo estuvo preso, salió y quiso ponerse a trabajar, pero no lo tomaron en ningún lado ni siquiera en la cooperativa donde trabaja mi tía (Iván).

En relación a los efectos del encierro penal que señalan los discursos juveniles en términos de que «te hace peor», o que «después de que salís ya no podés entrar a ningún lado por los antecedentes», sostiene Goffman (2001) que aunque el fin declarado de las «instituciones totales» es promover la reinserción social, durante la vida poscarcelaria la asignación de un estatus proactivo desfavorable (el de delincuente) impulsa al liberado a permanecer sujeto a la subcultura criminal, que a la vez probablemente lo reconduzca a la cárcel. Este «plus criminógeno» que produce el encierro aparece en los discursos juve- 
niles como propio de las medidas privativas de libertad a diferencia de lo que ocurriría en el caso de las medidas alternativas cuyo fin sería «ayudar» a los/as jóvenes, tanto en la causa como en el alejamiento del delito. Veamos algunos ejemplos:

En el tiempo en que yo estuve viniendo ellos se preocuparon por mi causa. Llaman a casa, preguntan cómo estoy, si trabajo, si me hace falta algo. Hicieron un ambiental, me ayudaron un montón. Yo estaba en un instituto, ellos movieron un par de papeles para que me dieran arresto domiciliario. Me querían poner una tobillera que si salís a 100 metros de tu casa empieza a sonar y a donde vayas te busca la policía y David lo rechazó (Brian).

A mí me ayudó un montón venir acá. Desde que vengo yo no me drogo más, no me junto más con los pibes, no hago macanas. El otro día, por ejemplo, fui hasta Merlo y me volví. Llegué y cuando estaba ahí la llamé a María y ella me ayudó a no tentarme con la situación de ir y volver a lo mismo (Lucas).

-Ellos lo que quieren saber es si es verdad que soy chorro o si tengo mala junta y ayudarme para que haga las cosas bien y que no haga boludeces. Van al barrio y preguntan si hacés junta, si te drogás, si te peleás, si hacés quilombo.

- ¿Les preguntan a tus vecinos?

-Sí, para ver cuál es tu comportamiento porque hay algunos que la caretean y se las remandan. Entonces, llegan al barrio y todo es distinto.

$-Y$ ¿ ¿a vos qué te parece que vayan al barrio?

-Bien, a mí me reayuda porque ellos se dan cuenta que yo soy siempre el mismo. (Franco)

Ayudar a corregir la conducta desviada y contribuir al cierre de la causa judicial son los principales atributos que los discursos juveniles conceden a las medidas alternativas. Se alude a una expectativa doble vinculada con los intereses de los/as jóvenes en un sentido estratégico (Bourdieu, 2010). Por un lado, la expectativa de mejorar las condiciones de la causa penal. Como en el caso de Brian, que a partir de un «movimiento de papeles» por parte de uno de los agentes del Centro de Referencia pudo salir de un dispositivo de encierro (un instituto) e ingresar en otro (la casa) pero sin estar ya alejado de la familia. De modo que se siente agradecido por dejar atrás el pasado vivido en el instituto y encontrarse en camino de recuperar la libertad por completo. O como el caso de Franco, quien está de acuerdo en que los operadores sociocomunitarios vayan a su barrio para ver si «en verdad es chorro», no porque le agrade que controlen su conducta sino porque al advertir que no «la caretea», le creen lo que dice que hace cuando va al Centro de Referencia. 
Por otro lado, existe también la expectativa de contar con la «ayuda» institucional en la transformación del comportamiento ilegal. Es el caso de Lucas que si bien va hasta el lugar donde se dispone a cometer un delito, antes de hacerlo recurre a la operadora sociocomunitaria para que, de alguna manera, lo frene. Como si no pudiera controlar por sí solo su comportamiento, pide ayuda para no repetir una situación que lo «tienta» pero a la que sabe que «no debe volver». En términos de Durkheim, antes de cometer un acto contra la moral, el joven siente algo que lo detiene «del mismo modo que cuando trata de alcanzar algo demasiado pesado para sus fuerzas» (1971, p. 51). La ayuda consiste aquí, diremos parafraseando a Bourdieu, en la contención de un acto tantas veces como el joven lo requiera, a fin de contribuir a que incorpore un aprendizaje del pasado capaz de permitir anticipaciones prácticas en el futuro. Es decir, a regularizar una conducta alejada del delito.

Estas dos finalidades principales atribuidas a las medidas alternativas, la primera que podríamos etiquetar como de carácter «instrumental» (contribuir al cierre de la causa judicial) y la segunda como de carácter «moral» (favorecer el desestimiento del delito y pagar por el daño ocasionado a la sociedad) habilitan la aprehensión de la conducta del joven como circunscripta al contexto (restrictivo) del Centro de Referencia. Si bien el sentido que tradicionalmente se atribuye al significante de ayuda posee una veta positivista (García-Méndez, \& Vitale, 2009) o asistencialista, creemos que los/as jóvenes no se posicionan simplemente en el lugar de protegidos o auxiliados por los agentes del Centro de Referencia. Veamos un ejemplo más:

- María me reayuda: se ocupa de mi salud, me quiere acompañar al psicólogo, me acompaña al hospital cuando tengo que hacerme un chequeo, cuando salgo del hospital me pregunta si tengo plata para el colectivo.

- ¿También te da plata para viajar?

-No, porque yo le digo que tengo. (Leonel)

Como se puede desprender del citado fragmento, si bien se sienten halagados al describir el modo en que los agentes institucionales «se ocupan» o pretenden ocuparse de sus problemas, los discursos juveniles no sitúan a los/as jóvenes como sujetos de tutela sino como sujetos que no desean recibir favores de los demás, sujetos conscientes de la situación en la que se encuentran y de que si la «aprovechan» pueden evitar no ser encerrados. En tal sentido, los/as jóvenes conciben la medida alternativa como un beneficio u oportunidad: 
Hay gente que se toma esto como si fuese una pérdida de tiempo, yo no pienso eso, para mí es un beneficio. Yo los escucho a ellos, no soy ningún boludo (Cristian).

Te dan la oportunidad de que cambies, si vos querés la agarrás. Es así (Martín).

Yo estoy re agradecido porque si no estuviera el juez de menores yo estaría en un penal y eso no es para mí. Por eso, trato de cumplir para que este año se cierre la causa. Yo ahora tengo esta oportunidad y pueden elevar que trabajo. Y eso está bien para ellos, o por lo menos para que el juez se conforme y para que vea que algo estoy haciendo y que no estoy en la calle (Mauro).

Las medidas alternativas están para que no vayas a un instituto directamente, para que vos puedas estar en la calle y no preso, les dan una oportunidad a los chicos para que puedan reflexionar y pensar mejor las cosas. El juez me dio una oportunidad por ser primerizo (Lucas).

En los discursos juveniles en torno a las medidas alternativas a la privación de libertad aparecen los significantes de beneficio y oportunidad que el Estado otorgaría a los/as jóvenes al no confinarlos en un dispositivo de encierro. Mediante esta forma de conceptualizar lo que desde otra perspectiva, como por ejemplo la del derecho penal clásico, podría entenderse como un derecho, los/as jóvenes se muestran «agradecidos» ante el juez y obligados a «no desaprovechar» lo que es dado. Saben que están en la cuerda floja y cualquier movimiento brusco que hagan los puede hundir en una institución de encierro penal. Un sitio que aparece en los discursos como no correspondido para ellos/as y les inspira temor, alarma y ansiedad. A salvo de tal pesadilla, los discursos juveniles construyen a los/as jóvenes intervenidos como haciendo todo lo que les pidan para «conformar al juez», escuchando y obedeciendo las «recomendaciones» de los agentes del Centro de Referencia.

\section{Discusión}

Partiendo del supuesto durkheimiano según el cual el castigo penal no sería eliminable de la estructura social de ninguna sociedad, este artículo se interesó por desentranar qué tipo de castigo constituyen las medidas alternativas a la privación de libertad a partir de discursos juveniles suscitados en el contexto de su implementación en nuestras sociedades contemporáneas. El fin fue establecer sus características principales y sus diferencias con las medidas privativas de libertad, desde las perspectivas de los propios jóvenes intervenidos. Maneras de comprender y de significar a través de las cuales es 
posible vislumbrar los procesos de aggiornamento o transformación sociocultural que la implementación de medidas alternativas a la privación de libertad viene a generar.

En tal sentido, podemos afirmar que en los discursos juveniles se concibió al castigo en libertad como preferible al castigo en el encierro ante todo por los efectos altamente estigmatizantes que esta última sanción supone. En línea con un conjunto de estudios que han señalado la contradicción de «resocializar» a una persona en un espacio segregado de la sociedad (Anitua, 2005, 2014; Bergalli, 2003; Cesaroni, 2009, 2010; GarcíaMéndez \& Vitale, 2009; Ghilberto \& Sozzo, 2016; López, 2012); dichas medidas aparecieron en los discursos juveniles como un nudo crítico del sistema de administración de justicia penal juvenil no solamente en términos de su ineficacia resocializadora sino también como experiencia extrema de soledad y violencia. Un castigo penal que los discursos juveniles señalaron como excesivo para jóvenes autores de delitos contra la propiedad.

Lo que habría que hacer con un joven que comete este tipo de infracciones es para los/as jóvenes hacerles «pagar» el daño ocasionado a la sociedad a través de formas de castigo menos angustiantes que el encierro como serían las medidas alternativas a la privación de libertad. He aquí la focalización de los discursos juveniles en la dimensión moral de un castigo que el joven y la joven debe cumplir para resarcir el daño ocasionado a la sociedad pero que debe conducir a reintegrarlo a ella y no a apartarlo en un dispositivo de encierro. En tal sentido, los y las jóvenes esbozaron los significantes de oportunidad y beneficio para dar cuenta de que toman conciencia de la posibilidad de cambio que les otorga el tránsito por el Centro de Referencia. Los discursos juveniles asociaron la oportunidad y el beneficio a la idea de reflexión, cambio, ayuda, dejar de estar detenido, no ser encerrado en un penal. Es decir, a la necesidad de alejarse de la transgresión (con tal de) no recibir un castigo mayor pero también por creer y desear la posibilidad de que la intervención alternativa transforme en algún aspecto su condición subalterna. Veamos una matriz de datos ilustrativa de los discursos juveniles en torno a las medidas privativas y alternativas a la privación de la libertad: 


\section{Tabla 1}

Discursos juveniles sobre el castigo

\begin{tabular}{|c|c|c|}
\hline & Moral (integración) & Penal (exclusión) \\
\hline $\begin{array}{l}\text { Medidas } \\
\text { alternativas a la } \\
\text { privación de la } \\
\text { libertad }\end{array}$ & $\begin{array}{l}\text { Deben dirigirse a jóvenes autores/as de } \\
\text { delitos contra la propiedad. } \\
\text { Son preferibles a la privación de la } \\
\text { libertad. } \\
\text { Constituyen un «beneficio» u } \\
\text { «oportunidad». } \\
\text { Implican «laburar de onda», } \\
\text { «mulear» (hacer trabajo comunitario). } \\
\text { Permiten la reflexión. } \\
\text { «Ayudan» (a evitar el encierro penal, a } \\
\text { alejarse del delito y a controlar las } \\
\text { adicciones). } \\
\text { Suponen acompañamiento. } \\
\text { Permiten «andar por la calle». } \\
\text { Suponen retribución (estar «pagando» por } \\
\text { el daño cometido). }\end{array}$ & \\
\hline $\begin{array}{l}\text { Privación de la } \\
\text { libertad }\end{array}$ & & $\begin{array}{l}\text { No creencia en la resocialización en } \\
\text { aislamiento («no sirve»). } \\
\text { El encierro produce dolor en el sujeto } \\
\text { privado de libertad y en su familia. } \\
\text { «Es injusto». } \\
\text { «Un pide de } 17 \text { no está preparado». } \\
\text { La cárcel supone «pelear por la comida, por } \\
\text { la cama, por todo» y «no estar tranquilo } \\
\text { nunca». } \\
\text { Produce resentimiento, «te vuelve más loco» } \\
\text { «estas con pibes malditos que la bardean } \\
\text { todo el día». } \\
\text { No sirve para educar en la obediencia legal. } \\
\text { Supone el estigma de tener antecedentes } \\
\text { penales. }\end{array}$ \\
\hline
\end{tabular}

Al interrogar a los/as jóvenes por el modo en que las medidas alternativas eran implementadas pudimos vislumbrar la perdurabilidad de prácticas asistencialistas vigentes durante el período previo a 2004 cuando se sanciona la ley de Promoción y Protección de los derechos del niño. Ello confirma los resultados hallados por el estudio de López et al. (2009) según el cual pese al transcurso de más de diez años de la sanción de dicha ley, en la actualidad sobreviven formas de intervención protectorias que no interpelan a los/as jóvenes como sujetos capaces de ejercer por sí mismos sus derechos. Sin 
embargo, la utilización del significante de ayuda en forma recurrente por los jóvenes y las jóvenes para señalar la finalidad de las medidas como orientada al cierre de la causa penal o a influir en la substitución del conjunto de códigos y costumbres desviadas de los/as jóvenes, no permite hipotetizar la asunción de la posición subjetiva a la que son convocados los/as jóvenes por los discursos y prácticas de los agentes del Centro de Referencia como sujetos de mera asistencia. De hecho, hemos subrayado durante el análisis que los/as jóvenes no se posicionan como sujetos de tutela sino como sujetos capaces de actuar a sabiendas de sus actos y de sus consecuencias. Quizás por eso, los discursos juveniles coinciden en señalar la apertura de los/as jóvenes para conversar con el personal del equipo técnico del Centro de Referencia en el marco de un proceso moral capaz de incidir en su subjetividad y su conducta futura.

Jóvenes que provienen de los sectores más vulnerables de la sociedad, que «no pueden comerse un buen asado» y desean hacerlo, lo cual los impulsaría a la transgresión. Este argumento coincide con una de las consideraciones de la tesis de González (2015) según la cual la implementación de medidas alternativas a la privación de libertad no se halla exenta de la selectividad del sistema penal, un sistema dentro del cual la individualización de la pena tiene una mayor carga criminalizante hacia jóvenes de sectores socialmente desfavorecidos que en aquellos jóvenes que tienen mayores ventajas económicas, elementos de socialización y derechos ejercidos (Couzo, 2006). Lo cual, como diría Beloff (2002), no significa que deba procederse derivando la imputación de un delito, automáticamente, de una supuesta situación donde el/la joven tendría un derecho amenazado. Al respecto, la autora propone analizar cada situación en particular asumiendo que la nueva justicia juvenil no apunta a «hacer el bien» al joven acusado/a de cometer un delito sino a provocarle un sufrimiento mínimo.

El sufrimiento apareció en los discursos juveniles sobre las medidas alternativas a la privación de la libertad en relación al cumplimiento de arresto domiciliario y la realización de tareas comunitarias. El arresto domiciliario se describió como «complicado» por el hecho de protagonizar los/as jóvenes su propio arresto así como también por los cambios en la rutina familiar que supone. Sin embargo, se lo concibió como preferible al encierro. Las tareas comunitarias, por su parte, se construyeron en los discursos como acciones pertinentes de desarrollar en el marco de la implementación de medidas alternativas pues a los/as entrevistados/as les parecía justo que los/as jóvenes infractores de la ley «paguen» por el daño ocasionado a la sociedad. El rechazo que esta medida suscitó por parte de los/as jóvenes intervenidos se debió al trato de subordinación, obediencia y 
docilidad desarrollado hacia ellos/as por parte de la comunidad (el sentimiento de que los hacían «limpiar», «laburar de onda», «mulear») en un contexto sumamente precario de restitución de derechos. El rechazo al trabajo comunitario fue un punto recurrente en los discursos así como también lo fue la preferencia de dicha medida por sobre medidas privativas de libertad. Con tal de no ser enviados a una institución de encierro, los/as jóvenes cumplen las tareas comunitarias y no quieren ni imaginar cómo sería su vida privados/as de libertad.

\section{Conclusión}

Los resultados formulados en torno a la pregunta de investigación orientada a indagar los sentidos que adquiere el significante de castigo en los discursos juveniles referidos a las medidas alternativas y las medidas privativas de libertad permiten señalar varias paradojas. En primer lugar, quisiéramos subrayar que ambas medidas son consideradas por los jóvenes en términos sancionatorios como medidas retributivas pero, en el caso de las medidas alternativas, el castigo puede dar lugar a la reintegración del joven en la comunidad luego de un proceso expiatorio que consiste en realizar trabajo comunitario como condición necesaria para el ingreso (simbólico) del joven a la sociedad. Se trata de un castigo moral tendiente a integrarlo a la comunidad sobre la base de estrategias de intervención socioeducativas en el sentido del conformismo y la apacibilidad, tanto en la comunidad como en el Centro de Referencia; a diferencia de la intervención privativa de libertad, la cual supone un proceso de desculturización ${ }^{12}$ (Baratta, 2004) que resulta penalmente estigmatizante para los jóvenes.

Respecto de las tareas comunitarias, sus efectos y su finalidad, nos gustaría plantear uno de los puntos que consideramos paradójicos en el marco de la implementación de medidas alternativas a la privación de la libertad. En primer lugar, el interrogante por el modo en que el ejercicio de esta sanción individualizada constituye o no, en el marco del modelo de los derechos del niño, una pena represiva «en el sentido de que la sanción fijada por la ley no consiste simplemente en poner las cosas en su estado: el delincuente

${ }_{12}$ Con proceso de desculturación Baratta se refiere a «la desadaptación a las condiciones que son necesarias para la vida en libertad (disminución de la fuerza volitiva, pérdida del sentido de autorresponsabilidad desde el punto de vista económico y social), la incapacidad para aprehender la realidad del mundo externo y la formación de una imagen ilusoria de él, el alejamiento progresivo de los valores y modelos de comportamiento propios de la sociedad exterior» (2004, p. 194). 
no está solo obligado a reparar el mal causado, sino que encima debe además alguna cosa, una expiación» (Durkheim, 2004, p. 95). Es decir, por la finalidad de una medida dirigida a un sujeto en formación, un joven, proveniente de los sectores más desprotegidos de la sociedad a quien no se lo busca empoderar políticamente sino hacerle protagonizar verdaderas «ceremonias de degradación» (Garfinkel, 2006, p. 115), tendientes a convertir la identidad pública del/la joven en algo concebido como inferior en el esquema local de tipologías sociales.

En segundo lugar y en relación a los efectos de las tareas comunitarias quisiéramos señalar una cuestión vinculada a los procesos de resignificación, oposición (o resistencia) efectuados por los jóvenes y las jóvenes que refiere al modo en que las tareas comunitarias pueden tener un fin moralizante, en distintos grados de concentración y violencia, o bien ejercerse en términos instrumentales con el objeto de evitar un castigo mayor. Si bien podemos pensarlas como un proceso de autoregulación interna que se busca promover en el joven desde las instituciones comunitarias, guiando su conducta en un sentido determinado por reglas (Durkheim, 1971), para que el cumplimiento de esas reglas de acción predetermine la conducta de los y las jóvenes es preciso que estos últimos las realicen no para impedir otro tipo de pena sino como fin en sí mismo. De otro modo, las fuerzas morales perderían su sacralidad, ese «no sé qué» que impone el respeto a la norma e impulsa a «conducirse con continuidad, según principios constantes superiores a los impulsos y sugestiones casuales» (Durkheim, 1971, p. 57). En tal sentido, pudimos advertir que los discursos juveniles a favor de las medidas alternativas se presentaron, ante todo, como discursos contra el encierro. Aquí el carácter «alternativo» de las medidas se revela como falaz pues, como sostiene Pavarini, «siguiendo esta estrategia, se crea una circularidad entre la cárcel y 'algo diferente de' la cárcel misma. Por esta vía, no se libera de la necesidad de la cárcel; al contrario, se afirma, de otra manera, su esencialidad» (Pavarini, 1999, p. 80). O, como agregaría Baratta: «todo reformismo tiene sus límites si no forma parte de una estrategia reduccionista a corto y mediano plazo y abolicionista a largo plazo respecto a la institución misma» (1990, p. 379).

Por todo lo dicho anteriormente, nos animamos a afirmar que más que de medidas «alternativas» se trata de medidas no privativas de libertad. Tal afirmación conlleva la limitación de realizarse sobre la base de los significados atribuidos a las medidas por parte de sus destinatarios/as y no del conjunto de actores (institucionales, comunitarios, 
judiciales, familiares, etc.) que constituyen el dispositivo. ${ }^{13}$ Sin embargo, creemos importante relevar la voz de los jóvenes y las jóvenes, sus formas de sentir y de pensar, en torno a dichas medidas como preferibles al encierro. En tal sentido, creemos que la pregunta que debemos hacernos en torno a los discursos juveniles que subrayan su predilección por las medidas alternativas es por el alcance de sus efectos descriminalizantes. En este punto seguimos a Park (2008) quien nos invita a pensar si el problema de status que les genera el hecho de reconocerse frente a la comunidad como teniendo que cumplir tareas comunitarias o arresto domiciliario puede impulsarlos a refugiar en la subcultura delictiva. Allí donde los valores que suponen el fracaso de los/as jóvenes rechazados pueden ser respetados; o, considerando que la conducta de los/as jóvenes se halla influenciada por la opinión pública del vecindario en tanto los obliga a actuar de acuerdo a sus códigos y reglas, si acaso la actitud receptiva hacia ellos/as en el marco del cumplimiento de dichas medidas puede posibilitar que su identidad desacreditada mejore y la comunidad comience a respetarlos/as y tratarlos/as como a un par más.

\section{Referencias}

Andrés-Candelas, M. (2016). La construcción socio-histórica de la «infancia peligrosa» en España. Revista Latinoamericana de Ciencias Sociales, Niñez y Juventud, 14(1), 95-106. https://doi.org/10.11600/1692715x.1417090915

Anitua, G. (2005). Historias de los pensamientos criminológicos. Buenos Aires: Editores del Puerto.

Anitua, G. (2014). Justificación del castigo. En J. Fabra, \& E. Spector (Eds.), Manual de Filosofía del Derecho (pp. 2109-2139). Ciudad de México: Instituto de Investigaciones Jurídicas de la UAM, Rubinzal Culzoni.

Ávila-Navarrete, V. C. (2017). ¿Corresponsabilidad familiar en instituciones de reeducación para adolescentes infractores? Revista Latinoamericana de Ciencias Sociales, Niñez y Juventud, 15(2), 1191-1206. https://doi.org/10.1160o/1692715x.1115080812

Axat, J., \& Rodríguez-Alzueta, E. (2014). Los pibes chorros. En S. Tonkonoff (Ed.), Violencia y cultura. Reflexiones contemporáneas sobre Argentina (pp. 173-210). Buenos Aires: Clacso.

\footnotetext{
${ }_{13}$ Dicha limitación se puede sortear recurriendo al conjunto de la tesis doctoral de la autora titulada «Juventud, responsabilidad y castigo. Un abordaje cultural de la cuestión criminal juvenil en la Argentina contemporánea», la cual se encuentra en la biblioteca de la Facultad de Ciencias Sociales de la Universidad de Buenos Aires.
} 
Baratta, A. (1990). Resocialización o control social: por un concepto crítico de «reintegración social» del condenado. Seminario Criminología Crítica y Sistema Penal. Comisión Andina de Juristas y Comisión Episcopal de Acción Social, Lima, Perú.

Baratta, A. (2004). Criminología crítica y derecho penal: introducción a la sociología jurídicopenal. Buenos Aires: Siglo XXI.

Beloff, M. (2002). Los adolescentes y el sistema penal: elementos para una discusión necesaria en la Argentina actual. Presentación leída en el Seminario para Auxiliares Docentes de Derecho Penal y Procesal Penal de la Facultad de Derecho. Universidad de Buenos Aires, Buenos Aires, Argentina.

Bergalli, R. (2003). Las funciones del sistema penal en el estado constitucional de derecho, social y democrático. En R. Bergalli (Ed.), Sistema Penal y problemas sociales (pp. 25-82). Valencia: Tirant Blanch.

Bourdieu, P. (1993). La miseria del mundo. Buenos Aires: Fondo de Cultura Económica.

Bourdieu, P. (2010). El sentido social del gusto: elementos para una sociología de la cultura. Buenos Aires: Siglo XXI.

Braithwaite, J. (2011). Delito, vergüenza y reintegración. Delito y Sociedad. Revista de Ciencias Sociales, 2(32), 7-18. https://doi.org/10.14409/dys.v2i32.5646

Cesaroni, C. (2009). El dolor como política de tratamiento. Buenos Aires: Fabián Di Placido Editor.

Cesaroni, C. (2010). La vida como castigo: los casos de adolescentes condenados a prisión perpetua en la Argentina. Buenos Aires: Grupo Editorial Norma.

Congreso de la Nación Argentina. (2019). Ley $N^{0}{ }^{1} 3298$. De la promoción y protección integral de los derechos de los niños, niñas y adolescentes. Buenos Aires: Congreso de la Nación Argentina.

Congreso de la Nación Argentina. (2019). Ley № 13 634. Del fuero de familia y del fuero penal del niño. Buenos Aires: Congreso de la Nación Argentina.

Corbalán, D., \& Rodríguez-Alzueta, E. (2016). ¡Rescátate! Puntos de partida provisorios para explorar las prácticas de sí. En E. Rodríguez-Alzueta (Ed.), Hacer bardo: provocaciones, resistencias y derivas de jóvenes urbanos (pp. 281-295) La Plata: Malisia.

Couzo, J. (2006). Principio educativo y (re)socialización en el derecho penal juvenil. En Justicia y derechos del niño. Artículos para el debate, jurisprudencia, documentos (pp. 5164). Santiago de Chile: Unicef.

Daroqui, A. (1995). El programa de libertad asistida cinco años después. Delito y Sociedad, 1(6/7), 67-76. https://doi.org/10.14409/dys.v1i6/7.5511

Durkheim, E. (1971). La educación moral. Buenos Aires: Schapire 
Durkheim, E. (1982). Las formas elementales de la vida religiosa: el sistema totémico en Australia. Madrid: Akal.

Durkheim, E. ([1967] 2004). La división del trabajo social. Buenos Aires: Libertador.

García-Méndez, E., \& Vitale, G. (Comps.) (20og). Infancia y democracia en la Provincia de Buenos Aires: comentario crítico sobre las leyes 13.298 y 13.634. Buenos Aires: Fundación Sur Argentina.

Garfinkel, H. (2006). Condiciones de las ceremonias exitosas de degradación. Delito y Sociedad. Revista de Ciencias Sociales, 1(22), 115-121. https://doi.org/10.14409/ dys.v1i22.5347

Ghilberto, L., \& Sozzo, M. (2016). El encierro dentro del encierro. Formas y dinámicas del aislamiento individual en las prisiones de varones y mujeres. Delito y Sociedad. Revista de Ciencias Sociales, 1(41), 109-155. https://doi.org/10.14409/dys.v1i41.6200

Goffman, E. (2001). Internados. Ensayo sobre la situación social de los enfermos mentales. Buenos Aires: Amorrortu.

Goffman, E. (2010). Estigma. La identidad deteriorada. Buenos Aires: Amorrortu.

González-Laurino, C. (2015). La infracción adolescente a la ley penal en el centro del debate sobre seguridad pública en Uruguay. Revista Latinoamericana de Ciencias Sociales, Niñez y Juventud, 13(2), 951-962. https://doi.org/10.11600/1692715x.13228201014

González, M. (2015). Discursos y prácticas en el Sistema de Responsabilidad Penal Juvenil: análisis de la implementación de las medidas alternativas a la privación de la libertad en el Centro de Referencia Penal Juvenil de Tandil. (Tesis de Licenciatura). Universidad Nacional del Centro de la Provincia de Buenos Aires, Facultad de Ciencias Humanas, Buenos Aires, Argentina.

Guemureman, S. (2008). La cartografía moral de las prácticas judiciales en los Tribunales de Menores. Los Tribunales Orales en la ciudad de Buenos Aires. (Tesis para optar por el título de Doctora en Ciencias Sociales). Universidad de Buenos Aires, Facultad de Ciencias Sociales, Buenos Aires, Argentina.

Jiménez, L., Meireles-Andrade, E., \& Guimarães Batistella Bianchini, L. (2016). Uso de drogas e ato infracional: revisão integrativa de artigos brasileiros. Revista Latinoamericana de Ciencias Sociales, Niñez y Juventud, 14(2), 939-955. https://doi.org/ 10.11600/1692715x.1417090915

Kessler, G. (2004). De proveedores, amigos, vecinos y barderos. Acerca del trabajo, delito y sociabilidad en jóvenes del Gran Buenos Aires, Desacatos, 14, 6o-84. https://doi.org/ 10.29340/14.1087 
Komatsu, A. V., \& Bazon, M. R. (2015). Caracterização de adolescentes do sexo masculino em relação a comportamentos antissociais. Revista Latinoamericana de Ciencias Sociales, Niñez y Juventud, 13(2), 725-735. https://doi.org/10.1160o/1692715x.13212210814 López, A. (2012). Contemplar desde los contornos: agencia judicial y centros de detención para jóvenes. Question, 36(1), 45-58.

López, A., Huber, B., Fridman, D., Graziano, F., Pasin, J., Azcárate ... Guemureman, S. (2009, noviembre). Reflexiones críticas sobre medidas alternativas a la privación de libertad para adolescentes en conflicto con la ley penal. XXVII Congreso Alas, Buenos Aires, Argentina.

Lucesole, N. (2012). Políticas públicas de niñez y adolescencia en la Provincia de Buenos Aires. Análisis del proceso de implementación del Sistema de Responsabilidad Penal Juvenil: un estudio de caso en el Centro de Referencia La Plata. (Tesis para optar por el título de Magíster en Diseño y Gestión de Políticas y Programas Sociales), Flacso, Buenos Aires, Argentina.

Medan, M. (2012). «¿Proyecto de vida?», tensiones en un programa de prevención del delito juvenil. Revista Latinoamericana de Ciencias Sociales, Niñez y Juventud, 10(1), 79-91. https://doi.org/10.1160o/1692715x.16215

Marcuello-Servós, C., \& García-Méndez, J. (2011). La cárcel como espacio de de-socialización ciudadana. ¿ ¿Fracaso del sistema penitenciario español? Portularia, 11(1), 49-60.

Nicoletti, M. (2014). Medidas alternativas al encierro: ¿un enunciado de buenos propósitos? Un estudio de caso sobre el Centro de Referencia La Plata. (Trabajo final de grado). Universidad Nacional de La Plata. Facultad de Humanidades y Ciencias de la Educación, Ciudad de La Plata, Argentina.

O'Malley, P. (2006). Riesgo, neoliberalismo y justicia penal. Buenos Aires: Ad- Hoc.

Oyhandy-Cioffy, A. (2004). La infancia en riesgo: entre la caridad y la ciudadanía. Un estudio de caso sobre la gestión de la infancia y la adolescencia en riesgo en la Argentina contemporánea: La Plata, 2000- 2003. (Tesis para optar el grado de Maestro en Ciencias Sociales). Flacso, Ciudad de La Plata, Argentina.

Park, R. (2008). La organización de la comunidad y la delincuencia juvenil. Delito y Sociedad. Revista de Ciencias Sociales, 1(25), 115-124. https://doi.org/10.14409/dys.v1i25.5882

Pavarini, M. (1999). Dossier Cárcel: ¿menos cárcel y más medidas alternativas? Delito y Sociedad. Revista de Ciencias Sociales, 1(2), 75-85. https://doi.org/10.14409/dys.vii2.100 Pavarini, M. (2006). Un arte abyecto: ensayo sobre el gobierno de la penalidad. Buenos Aires: Ad Hoc. 
Rodríguez-Alzuelta, E. (2014). Temor y control: la gestión de la inseguridad como forma de gobierno. Buenos Aires: Futuro Anterior.

Tarde, G. (1952). Filosofía penal. Madrid: Moderna.

Tenembaum, G. (2015). La detención policial de adolescentes en Uruguay: percepciones y experiencias. Revista de la Facultad de Derecho, 39, 227-258. https://doi.org/ $10.22187 / 201529$

Tenembaum, G. (2016). Infracción y castigo. Los procesos de normalización para adolescentes con medidas en libertad en la Ciudad de México y Montevideo. (Tesis de Doctorado). Colegio de México, Ciudad de México, México.

Tonkonoff, S. (2007a.) Juventud, exclusión y delito: notas para la reconstrucción de un problema. Alegatos, 65, 33-46.

Tonkonoff, S. (2007b.) Tres movimientos para explicar por qué los pibes chorros visten ropas deportivas. Sociología ahora. Buenos Aires: Siglo XX, FSOC, Universidad de Buenos Aires.

Tonkonoff, S. (2012). La cuestión criminal: ensayo de (re)definición. Nómadas. Revista Crítica de Ciencias Sociales y Jurídicas, 35(3), 1-27. https://doi.org/10.5209/rev_noma. 2012.v35.113.42203

Uriarte, C. (2013). La cuestión de la responsabilidad en el derecho penal juvenil. En C. González-Laurino, S. Leopold-Costábile, L. López-Gallego, \& P. Martinis (Coords.) Los sentidos del castigo: el debate uruguayo sobre la responsabilidad en la infracción adolescente (123-141). Montevideo: Universidad de la República.

Valdenegro, B., \& Calderón-Flández, C. (2016). Alteridad, infancia y delincuencia: análisis discursivo desde programas sociales hacia infancias en Chile. Revista Latinoamericana de Ciencias Sociales, Niñez y Juventud, 14(2), 1191-1204. https://doi.org/ 10.11600/1692715x.1417090915

Vasilachis de Gialdino, I. (2006). Estrategias de investigación cualitativa. Buenos Aires: Gedisa. 